\title{
The Effect of Varied-Intensity Physical Exercises on Some Physical and Physiological Variables to Improve the Performance Level in Sports Shows
}

\author{
Samir Abdel-Naby Shaaban Issa ${ }^{1}$, El-Sayed Soliman Hammad ${ }^{2}$ \\ ${ }^{1}$ Assistant Professor, Exercises and Gymnastics Training Department, Faculty of Sport Education for Men, Alexandria \\ University, Egypt \\ ${ }^{2}$ Assistant Professor, Sport Biological and Health Sciences Department, Faculty of Sport Education for Men, Alexandria \\ University, Egypt
}

\begin{abstract}
:
The study aims at identifying the effect of varied-intensity physical exercises on some physical and physiological variables to improve the performance level in sports shows. The experimental approach was used for its relevance to the nature of the research, using the pre-post-measurements. The study was conducted to a sample of (24) first grade students of the Faculty of Physical Education for Boys, Alexandria University, the students were assigned to participate in the Republic's championship for the sport shows of the specialized faculties, where the physical variables and physiological measurements were measured and the researchers designed a sport show that has been learned and trained for a period of (10) weeks, with (3) training sessions per week. The results showed that the experimental group in the post-measurements exceeded the pre-measurements in all physical and physiological variables of the respiratory and circulatory systems of the first grade students of the Faculty of Physical Education for Boys. The performance level in the sport show has improved in the post-measurement in contrary of the pre-measurement. The sport show has got the first place of the Republic's championship for the sport shows of the specialized faculties in 2017, and according to these results, the researchers recommend to direct the students to participate in the sports shows that contribute to the improvement of the physical and physiological variables, of the respiratory and circulatory systems, use and functionalize the exercise tools and equipment in the sport shows appropriately, and conduct physiological measurements regularly to identify the extent of the response of the respiratory and circulatory systems to meet the requirements of the sport shows of the students of the Faculty of Physical Education.
\end{abstract}

Introduction and Research Problem:

$\mathrm{V}$ ital organs of the body do not work independently as there are close links and different interactions between them, so doctors and health scientists are concerned about the individual's need to have an optimal level of physiological fitness because this level reflects the individual's health status, and in order to identify this level we should use the physiological devices to measure the physiological responses of the various body organs and systems. $(13: 187)$

During the development processes of the athletic status affected by the physical training, the athlete's organs gain a special state known as the training status which occurs due to the changes in the characteristics of the vital organs under the effect of the physical training processes, and the training status is characterized by a specific level of physical efficiency. $(1: 156)$

In resting state, there can be obvious differences in the training status between the trained athletes and the untrained ones in the functions of the different body organs $(1: 164)$. The respiratory functions are often used to measure as an index to the health fitness, as they relate to the potential abilities for the individuals' superiority in the varied-intensity aerobic performances. (34:400)

Codified physical training and its physical and technical requirements are the most important factors that lead to the improvement of the physiological processes, and provide the practitioners with some physiological changes that occur under the effect of the regular training loads, because the programs and training loads are considered as stimulants that raise the physiological, physical and 
technical levels to achieve the highest levels. (31:70) (5 :17)

Training programs are designed to raise the level of physical and physiological levels, develop the body systems to improve the motor activity in order to achieve the highest levels through the physical exercises as they are the basis for improving the vital organs of the human body (27:9). Determining the intensity of physical loads is linked to the various physical activities and it is related to the physiological activity of the athlete's organs. (1:132)

Physical abilities are obviously necessary for the individual as they are associated to the achievement of the specialized sports activity. These abilities include flexibility, explosive power, endurance, agility, harmony, balance and velocity, and they are integrated with each other in a reflective effect to complete and accomplish the performed movement well. (21:22) (26:1) (44:15)

Sport shows and its physical and motor requirements improve many physiological processes and the practiced exercises work as motor stimuli that work on raising the physical, physiological and motor levels and perhaps endurance is the most affected element by the sport shows. $(17: 36)$

Endurance in sport activities is based on the interactions between aerobic and anaerobic abilities; therefore reaching a high level in any activity must be linked to a good level of aerobic and anaerobic endurances. $(15: 12)$

Endurance training is the applied field of energy production systems as organizing the endurance training and assuring its efficiency require precise guidance and complete observation of the changes in the aerobic and anaerobic abilities, so the practical objectives of endurance training cannot be achieved without applying the aerobic and anaerobic energy production systems. (7:2) (19:57)

Organizing the sport shows events in which the specialized faculties participate throughout the republic is an annual tradition for these colleges. The conditions of this competition depend on performing the sport show by each faculty for 5-6 minutes; hence the researchers thought of training the students according to the energy production systems to help the students reach the highest level. Howley and Franks (1997) show that the contribution of energy from aerobic and anaerobic sources is determined by intensity and permanence. Activities that take less than a minute follow the anaerobic system, while activities that take 2-3 minutes use both anaerobic and aerobic systems with $50 \%$ each, while the percentage of contribution of anaerobic is only $15 \%$ in the activities that last for 10 minutes. (25:52)
Hayes (1998) confirms that according to the division of energy production systems according to the time of performance in sports activities, which takes 4 minutes or more, which is the subject of the current study, glycogen and fatty acids are the source of energy, due to the aerobic oxygen energy system. $(22: 73)$

Endurance is divided according to the energy production systems to short period endurance, which takes from 45 seconds to two minutes (anaerobic endurance), moderate period form 2-8 minutes (mixed endurance "aerobicanaerobic"), and long period endurance which takes more than 8 minutes. $(15: 31-36)(11: 231-233)$

At this point the researchers see the possibility of functionalizing the moderate periodic training (slow and fast) to develop the mixed endurance so as to determine its effect on some physical and physiological variables through designing and training for a sport show.

\section{Research Objective:}

The research aims at identifying:

1- the effect of varied-intensity physical exercises on some physical variables to improve the performance level in sports shows for the first grade students of the Faculty of Physical Education.

2- the effect of varied-intensity physical exercises on some physiological variables to improve the performance level in sports shows for the first grade students of the Faculty of Physical Education.

\section{Research Hypotheses:}

1- There are statistically significant differences between the pre- and post-measurements in some physical variables for the first grade students of the Faculty of Physical Education in favor to the post-measurement.

2- There are statistically significant differences between the pre- and post-measurements in some physiological variables for the first grade students of the Faculty of Physical Education in favor to the post-measurement.

\section{Research Methodology:}

The experimental approach was used for its relevance to the nature of the research, using the pre- postmeasurements.

\section{Research domains:}

\section{Spatial domain:}


Exercises and gymnastics hall at the Faculty of Physical Education for Boys, Alexandria University, Physical Stress Physiology Laboratory, Faculty of Physical Education for Girls, Alexandria University.

\section{Temporal domain:}

The research was conducted during the period from $21 / 1 / 2017$ to $30 / 3 / 2017$, and the following table illustrates the time distribution of the research procedures:

Table (1)

Time distribution of the research procedures

\begin{tabular}{|c|c|}
\hline Procedures & Period \\
\hline Pre-measurements were conducted & $21 / 1 / 2017-26 / 1 / 2017$ \\
\hline The experiment was conducted & $28 / 1 / 2017-23 / 3 / 2017$ \\
\hline Pre-measurements were conducted to evaluate the performance level in the sport show & $9 / 2 / 2017$ \\
\hline Post-measurements were conducted for all of the variables and performance level in the sport show & $25 / 3 / 2017-30 / 3 / 2017$ \\
\hline
\end{tabular}

\section{Human domain:}

The study was conducted on a sample consisted of the first grade students of the Faculty of Physical Education for Boys, Alexandria University.

\section{Research Sample:}

The study was conducted to a sample of (24) first grade students of the Faculty of Physical Education for Boys, Alexandria University.

\section{Reasons of selecting the sample:}

1- The individuals of the sample were at the same age group.

2- The ease of the presence of the sample individuals in the training times on the sport show to take the measurements at the faculty campus.

3- The students were assigned to participate in the Republic's championship for the sport shows of the specialized faculties and discharging them from the lectures.

\section{Data Collecting Tools:}

\section{I) Physical tests: Attachment (1)}

1- Maximum power (power of the right fist and left fist)

2- Explosive power (pushing a $3 \mathrm{~kg}$ medical ball with the right arm, left arm and both arms), and rope jump (10 sec.)

3- Agility (sloping pronation of standing $10 \mathrm{sec}$.

4- Compatibility (rope jump to circularity, numbered circles)
5- Balance (fixed "instep on a cube", motor "walking on a balance beam")

6- Reaction velocity eye / hand (right), eye / hand (left) (40), (32), (33)

II) Physiological measurements: using the spirometer: Attachment (2)

1- Tidal Volume (TV)

2- Vital Capacity (VC)

3- Forced Vital Capacity (FVC)

4- Inspiratory Capacity (IC)

5- Inspiratory Reserve Volume (IRV)

6- Forced Expiratory Volume in 1 second (FEV1)

7- Expiratory Reserve Volume (ERV)

8- Peak Expiratory Flow Rare (PEFR) (2), (13), (34), (20)

\section{III) Evaluation of the sport show:}

A committee from the Exercises and Gymnastics Training Department, Faculty of Physical Education for Boys, Alexandria University, which is consisted of (5) specialized judges, was formed to evaluate the performance level in the sport show using the evaluation form of the Republic's championship for the sport shows. Attachment (3)

\section{Sample homogeneity:}


Table (2)

Statistical significances of the measurements and physical tests of the total research sample $(n=24)$

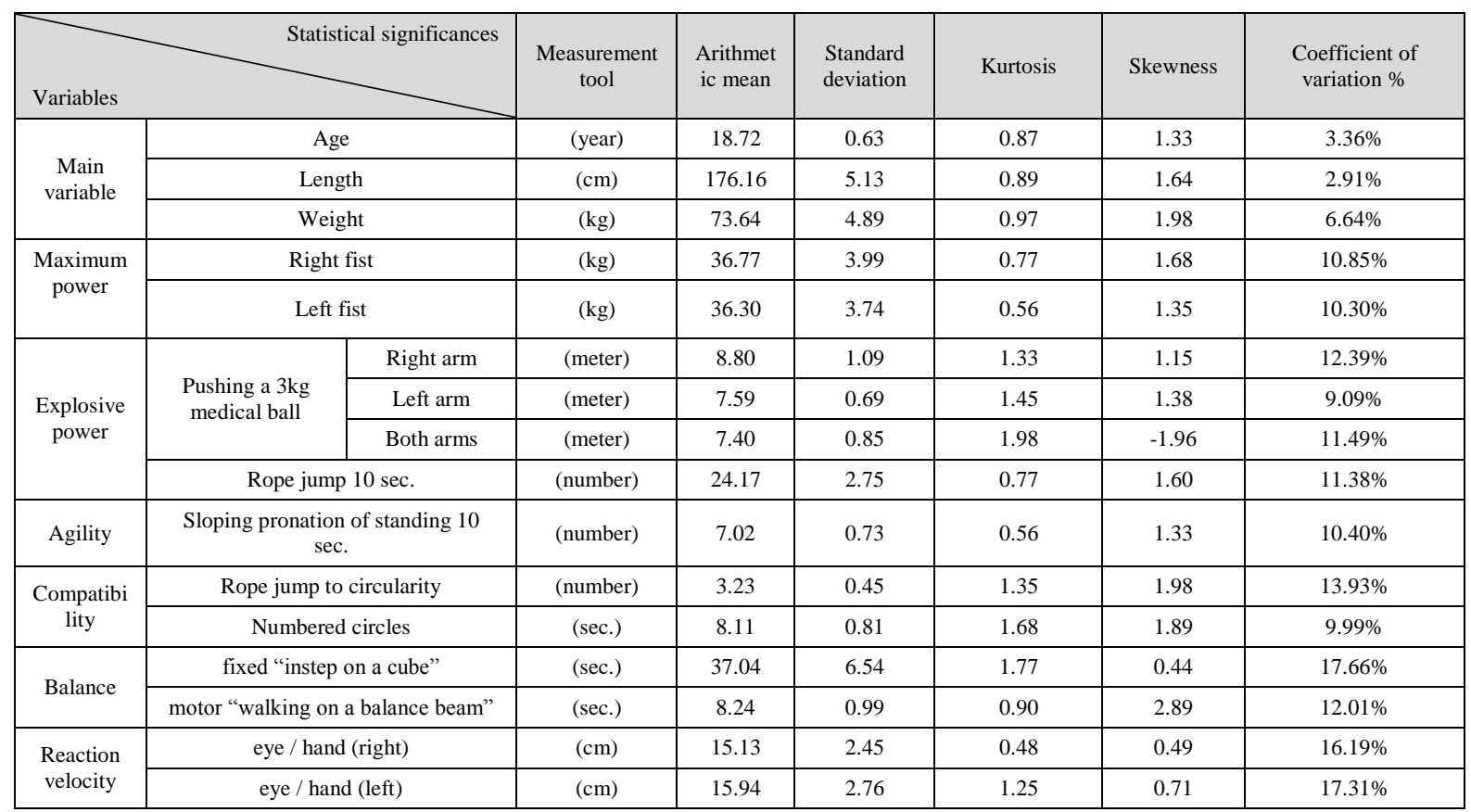

Table (2) shows that the values of skewness ranged between (-1.96) and (2.89), therefor, the values ranged between $( \pm 3)$ and this confirms the homogeneity of the sample. The coefficient of variation of the main and physical variables of the total sample ranged between $(2.91 \%)$ and $(17.66 \%)$, which is $20 \%$ less than the mean, indicating the homogeneity of the research sample to all of the main and physical variables under study.

Table (3)

Statistical significances of the physiological variables of the total research sample $(n=24)$

\begin{tabular}{|c|c|c|c|c|c|c|}
\hline Statistical significances & $\begin{array}{c}\text { Measurement } \\
\text { tool }\end{array}$ & $\begin{array}{c}\text { Arithmetic } \\
\text { mean }\end{array}$ & $\begin{array}{c}\text { Standard } \\
\text { deviation }\end{array}$ & Kurtosis & $\begin{array}{c}\text { Skewness } \\
\text { of variation } \\
\%\end{array}$ \\
\hline Tidal Volume (TV) & (liter) & 0.60 & 0.03 & 1.08 & 1.23 & $4.26 \%$ \\
\hline Vital Capacity (VC) & (liter) & 4.25 & 0.32 & 0.20 & -0.06 & $7.50 \%$ \\
\hline Forced Vital Capacity (FVC) & (liter) & 4.34 & 0.49 & 1.46 & 2.74 & $11.20 \%$ \\
\hline Inspiratory Capacity (IC) & (liter sec.) & 3.29 & 0.14 & -0.24 & 0.40 & $4.30 \%$ \\
\hline Inspiratory Reserve Volume (IRV) & (liter) & 2.75 & 0.10 & -0.17 & -1.02 & $3.71 \%$ \\
\hline Expiratory Volume In 1 First Second Forced & (liter sec.) & 3.64 & 0.35 & -0.10 & -1.38 & $9.65 \%$ \\
\hline (FEV1) & (liter) & 1.24 & 0.09 & -0.14 & -1.18 & $7.65 \%$ \\
\hline Expiratory Reserve Volume (ERV) & (liter sec.) & 6.88 & 1.07 & 0.06 & -1.16 & $15.61 \%$ \\
\hline Peak Expiratory Flow Rare (PEFR)
\end{tabular}

Table (3) shows that the values of skewness ranged between (-1.38) and (2.74), therefor, the values ranged between $( \pm 3)$ and this confirms the homogeneity of the sample. The coefficient of variation of the physiological variables of the total sample ranged between $(3.71 \%)$ and $(15.61 \%)$, which is $20 \%$ less than the indicating the homogeneity of the research sample to all of the physiological variables under study. 
Table (4)

Statistical significances of the evaluation form at the middle of the experiment $(n=5)$

\begin{tabular}{|c|c|c|c|c|c|c|c|}
\hline \multicolumn{2}{|l|}{ Variables } & Score & $\begin{array}{l}\text { Arithmetic } \\
\text { mean }\end{array}$ & $\begin{array}{l}\text { Standard } \\
\text { deviation }\end{array}$ & Kurtosis & Skewness & $\begin{array}{c}\text { Coefficient of } \\
\text { variation \% }\end{array}$ \\
\hline \multirow{3}{*}{ First axis } & Entry & 5 points & 2.68 & 0.39 & -1.94 & 1.17 & $14.55 \%$ \\
\hline & Formations and groups & 15 points & 7.68 & 0.18 & 2.24 & 1.00 & $2.33 \%$ \\
\hline & Total & 20 points & 10.36 & 0.46 & -1.49 & 2.82 & $4.40 \%$ \\
\hline \multirow{5}{*}{$\begin{array}{l}\text { Second axis } \\
\text { (technical } \\
\text { performance) }\end{array}$} & Sequential performance & 8 points & 4.68 & 0.39 & -1.94 & 1.17 & $8.33 \%$ \\
\hline & Flow of the movement & 8 points & 4.02 & 0.30 & -1.84 & 1.26 & $7.55 \%$ \\
\hline & Difficulties & 8 points & 2.68 & 0.18 & 2.14 & 2.00 & $6.67 \%$ \\
\hline & $\begin{array}{c}\text { Good equipment } \\
\text { placement }\end{array}$ & 8 points & 4.12 & 0.11 & -0.61 & -1.33 & $2.66 \%$ \\
\hline & Total & 32 points & 15.50 & 0.55 & 0.08 & -1.88 & $3.53 \%$ \\
\hline \multirow{3}{*}{ Third axis } & Clothing & 10 points & 7.60 & 0.55 & -0.61 & -1.33 & $7.21 \%$ \\
\hline & Music & 15 points & 11.92 & 0.72 & 0.54 & 1.91 & $6.00 \%$ \\
\hline & Total & 25 points & 19.52 & 0.58 & -0.59 & -2.85 & $2.95 \%$ \\
\hline \multirow{4}{*}{ Fourth axis } & Output & 15 points & 11.76 & 0.22 & 0.61 & -1.33 & $1.86 \%$ \\
\hline & Display time & 5 points & 5.00 & 0.00 & 0.00 & 0.00 & $0.00 \%$ \\
\hline & Ending & 3 points & 1.72 & 0.22 & 0.56 & -2.37 & $12.60 \%$ \\
\hline & Total & 23 points & 18.48 & 0.36 & 0.60 & -0.23 & $1.93 \%$ \\
\hline \multicolumn{2}{|c|}{ Total score of the show } & 100 points & 63.86 & 0.66 & 0.45 & -0.25 & $1.03 \%$ \\
\hline
\end{tabular}

Table (4) shows that the data of the research sample is moderate, non-dispersed and normally distributed, where skewness ranged between (-1.94) and (2.24), therefor, the values ranged between to \pm 3 and were close to zero. This confirms that the sample is free of defects of the nonmoderate distributions, also the coefficient of variation ranged between $0.00 \%$ and $14.55 \%$ and these values are less than $20 \%$, which confirms that the sample members were homogenous after two weeks of conducting the experiment.

\section{Main experiment:}

- The research group learned how to make the formations and groups in the first week.
- The research group started training and reviewing the safety of positions and correction of errors from the second week.

- Periodic training is divided according to the training time into a short period (15) to (120) seconds to improve the anaerobic endurance, moderate period (2-8) minutes to improve of the mixed endurance, and long period (8-15) minutes to improve the aerobic endurance.

\section{$(15: 172-176)$}

The moderate period training (slow and fast) was used according to the proposals of Sharkey (1997) regarding the moderate training $(41: 107)$ within 10 weeks, with three sessions per week.

1- Pulse of hand palm $=71 \mathrm{p} / \mathrm{min}$.

2- Calculate the maximum pulse $=220$ - age

$$
=220-19=201 \mathrm{p} / \mathrm{min} \text {. }
$$

3- Calculating the pulse reserve $=$ maximum pulse - pulse of hand palm

$$
=201-71=130 \mathrm{p} / \mathrm{min} \text {. }
$$

4- The intensity ranges between $70 \%-85 \%$.

\section{0}

5- Target pulse with intensity of $70 \%=-\times$ pulse reserve + pulse of hand palm

100

$$
\begin{aligned}
& =0.7 \times 130+71 \\
& =160 \mathrm{p} / \mathrm{min} .
\end{aligned}
$$


Target pulse with intensity of $85 \%=180 \mathrm{p} / \mathrm{min}$.

- Therefor, the target pulse training is between $160 \mathrm{p} / \mathrm{min}$. and $180 \mathrm{p} / \mathrm{min}$.

6- Performance time: (1.30-3) minutes for group exercises, and (5-7) minutes for the whole show.

7- Pulse of inter-palm: (120-130) p / min.

8- Number of groups: (2-3) times.

9 - Routines: (3-5) times to practice the group exercises or the whole show.

10 - Rest time: (3-5) minutes to practice the group exercises, and (10-15) minutes for the whole show.

11- Rate of action to rest: (1:2)

12- Attachment (7) shows a model for a training session.

Content of the Presentation: Attachment (5)

I) Presentation title: "Hope Makers"

II) Presentation idea: Attachment (5)

III) Formations, groups and exercises:

The following criteria were taken into consideration:

- Diversity and innovation in exercise according to the tool of the show.

- Ease of transition from one formation to another.

- Diversity in using the formations and groups.

- Suitability of the exercises to the formations of the show, revealing the contrast of each formation.

- Passing through the (high - medium - low) levels.

- Students' ability to perform the selected exercises.

- The exercises involve all of the body parts.

- Good utilizing of the tool in the exercise.

\section{IV) Equipment:}

- $\quad$ (8) $(210 \mathrm{~cm})$ parallel bars

- A painting which represents the flag of Egypt and the Pyramids, with the title of the show was used as the show's background.

\section{V) Uniform:}

- (24) shirts and trousers colored with the flag of Egypt.
- (24) white socks.

\section{VI) Components of the presentation:}

- The show consisted of an entry, (12) formations and an ending. Attachment (5).

\section{VII) Music:}

- A musical composer set the music of the show with 120 beats per minute to 148 beats per minute.

\section{VIII) Lighting:}

- The show was held in the covered hall at AlItihad Sport Club, and the spotlights were used.

\section{Statistical Treatments:}

SPSS application was used to find the following statistical treatments:

- $\quad$ Arithmetic mean

- Standard deviation

- Skewness

- Kurtosis

- Coefficient of variation

- $\quad$ Paired-samples T Test

- Percentile of improvement

- ETA $^{2}$ coefficient

- Effect size according to Cohen. 
Presentation and Discussion of the Results:

Table (5)

Statistical significances of the physical variables between the pre- and post-measurements $(n=24)$

\begin{tabular}{|c|c|c|c|c|c|c|c|c|c|c|c|}
\hline \multirow[b]{2}{*}{ Variables } & & \multirow[t]{2}{*}{$\begin{array}{r}\text { Statistical } \\
\text { significances }\end{array}$} & \multirow{2}{*}{$\begin{array}{l}\text { Measurement } \\
\text { unit }\end{array}$} & \multicolumn{2}{|c|}{ pre-measurement } & \multicolumn{2}{|c|}{ post-measurement } & \multicolumn{2}{|c|}{$\begin{array}{l}\text { Differences } \\
\text { between the } \\
\text { means }\end{array}$} & \multirow[t]{2}{*}{ (t) value } & \multirow[t]{2}{*}{$\begin{array}{l}\text { Percentage of } \\
\text { improvement }\end{array}$} \\
\hline & & & & $\mathrm{X}$ & $\pm \mathrm{P}$ & $\mathrm{X}$ & $\pm \mathrm{P}$ & $\mathrm{X}$ & $\pm \mathrm{P}$ & & \\
\hline \multirow{2}{*}{$\begin{array}{l}\text { Maximum } \\
\text { power }\end{array}$} & \multicolumn{2}{|c|}{ Right fist } & $(\mathrm{kg})$ & 36.77 & 3.99 & 41.18 & 3.47 & 4.41 & 1.23 & $5.77 *$ & $9.44 \%$ \\
\hline & \multicolumn{2}{|c|}{ Left fist } & $(\mathrm{kg})$ & 36.30 & 3.74 & 39.73 & 4.62 & 3.43 & 0.45 & $4.00 *$ & $12.73 \%$ \\
\hline \multirow{4}{*}{$\begin{array}{l}\text { Explosive } \\
\text { power }\end{array}$} & \multirow{3}{*}{$\begin{array}{l}\text { Pushing } \\
\text { a } 3 \mathrm{~kg} \\
\text { medical } \\
\text { ball }\end{array}$} & Right arm & (meter) & 8.80 & 1.09 & 9.79 & 0.82 & 1.00 & 0.21 & $5.07 *$ & $9.32 \%$ \\
\hline & & Left arm & (meter) & 7.59 & 0.69 & 8.61 & 0.53 & 1.02 & 0.23 & $8.07 *$ & $6.98 \%$ \\
\hline & & Both arms & (meter) & 7.40 & 0.85 & 8.02 & 0.69 & 0.62 & 0.11 & $3.94 *$ & $9.32 \%$ \\
\hline & \multicolumn{2}{|c|}{ Rope jump 10 sec. } & (number) & 24.17 & 2.75 & 26.94 & 2.25 & 2.77 & 0.54 & $5.40 *$ & $10.29 \%$ \\
\hline Agility & \multicolumn{2}{|c|}{$\begin{array}{l}\text { Sloping pronation of } \\
\text { standing } 10 \mathrm{sec} .\end{array}$} & (number) & 7.02 & 0.73 & 7.56 & 0.74 & 0.54 & 0.06 & $3.61 *$ & $9.31 \%$ \\
\hline \multirow{2}{*}{ Compatibility } & \multicolumn{2}{|c|}{ Rope jump to circularity } & (number) & 3.23 & 0.75 & 4.02 & 0.73 & 0.79 & 0.16 & $5.24 *$ & $10.54 \%$ \\
\hline & \multicolumn{2}{|c|}{ Numbered circles } & (sec.) & 8.11 & 0.81 & 7.59 & 0.61 & 0.52 & 0.03 & $3.54 *$ & $22.60 \%$ \\
\hline \multirow[b]{2}{*}{ Balance } & \multicolumn{2}{|c|}{ fixed "instep on a cube" } & (sec.) & 37.04 & 6.54 & 45.04 & 6.52 & 7.00 & 1.44 & $3.26^{*}$ & $7.52 \%$ \\
\hline & \multicolumn{2}{|c|}{$\begin{array}{l}\text { motor "walking on a } \\
\text { balance beam" }\end{array}$} & (sec.) & 8.24 & 0.99 & 7.40 & 0.47 & 0.84 & 0.56 & $5.30 *$ & $17.60 \%$ \\
\hline \multirow{2}{*}{$\begin{array}{l}\text { Reaction } \\
\text { velocity }\end{array}$} & \multicolumn{2}{|c|}{ eye / hand (right) } & $(\mathrm{cm})$ & 15.13 & 4.45 & 12.23 & 4.23 & 3.10 & 0.23 & $3.17 *$ & $27.96 \%$ \\
\hline & \multicolumn{2}{|c|}{ eye / hand (left) } & $(\mathrm{cm})$ & 15.94 & 3.76 & 12.40 & 3.74 & 3.54 & 0.57 & $3.02 *$ & $23.46 \%$ \\
\hline
\end{tabular}

(t) value at the level of $0.05=\mathbf{2 . 0 6 9}$

Table (5) and Figure (1) show that there are statistically significant differences at (0.05) in all physical variables in favor to the post-measurement, where the calculated $(\mathrm{t})$ value ranged between (3.02) and (8.07), which is greater than the tabulated $(\mathrm{t})$ value at $(0.05)=(2.069)$ with a percentage of improvement ranged between $(6.98 \%)$ and $(27.96 \%)$.

Figure (1)

Arithmetic mean of the pre- and post-measurements of the physical variables

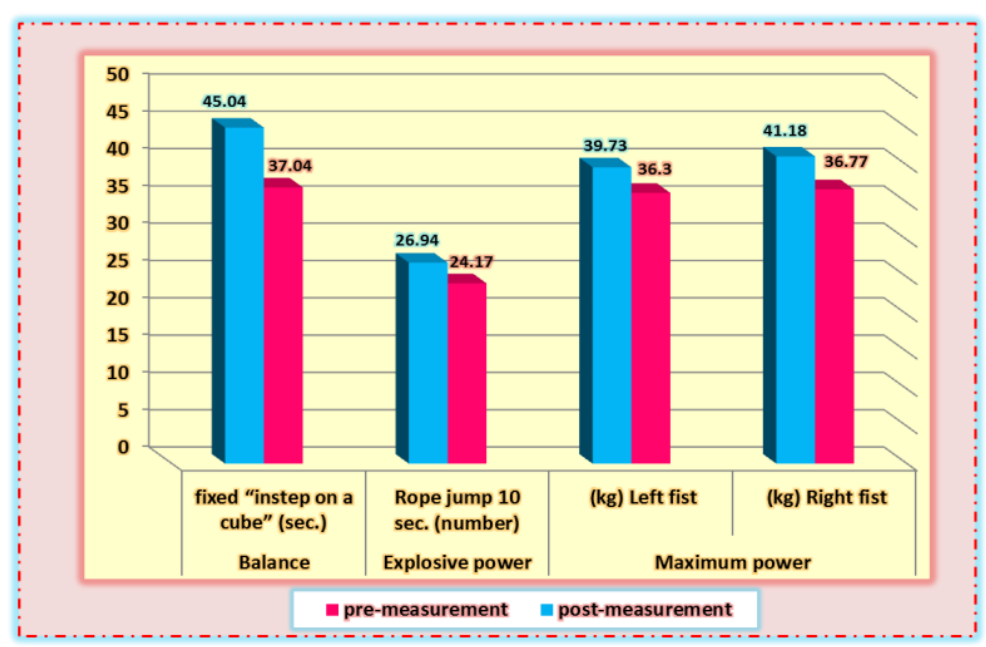



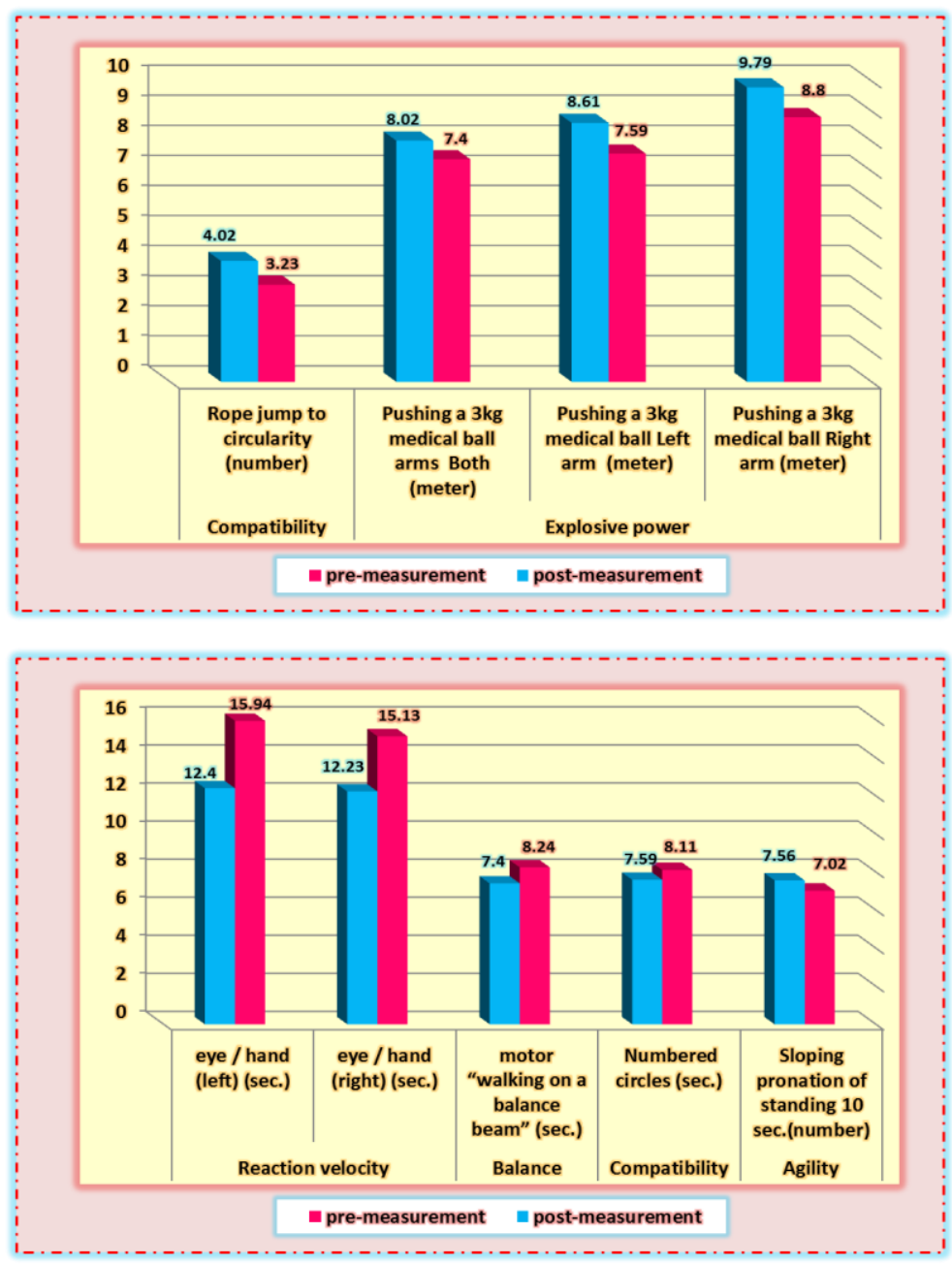

Table (6)

Statistical significances of the physiological variables for the pre- and post-measurements $(n=24)$

\begin{tabular}{|c|c|c|c|c|c|c|c|c|c|}
\hline \multirow[b]{2}{*}{ Variables } & \multirow{2}{*}{$\begin{array}{l}\text { Measureme } \\
\text { nt unit }\end{array}$} & \multicolumn{2}{|c|}{$\begin{array}{c}\text { pre- } \\
\text { measurement }\end{array}$} & \multicolumn{2}{|c|}{ post-measurement } & \multicolumn{2}{|c|}{$\begin{array}{l}\text { Differences between the } \\
\text { means }\end{array}$} & \multirow{2}{*}{$\begin{array}{c}(\mathrm{t}) \\
\text { value }\end{array}$} & \multirow{2}{*}{$\begin{array}{l}\text { Percentage of } \\
\text { improvement }\end{array}$} \\
\hline & & $\mathrm{X}$ & $\pm \mathrm{P}$ & $\mathrm{X}$ & $\pm \mathrm{P}$ & $\mathrm{X}$ & $\pm \mathrm{P}$ & & \\
\hline Tidal Volume (TV) & (liter) & 0.60 & 0.03 & 0.81 & 0.07 & -0.21 & 0.09 & $11.66 *$ & $35.24 \%$ \\
\hline Vital Capacity (VC) & (liter) & 4.25 & 0.32 & 6.11 & 0.44 & -1.86 & 0.65 & $14.03 *$ & $43.66 \%$ \\
\hline Forced Vital Capacity (FVC) & (liter) & 4.34 & 0.49 & 6.27 & 0.39 & -1.93 & 0.54 & $17.68 *$ & $44.58 \%$ \\
\hline Inspiratory Capacity (IC) & (liter sec.) & 3.29 & 0.14 & 4.54 & 0.20 & -1.25 & 0.26 & $23.17 *$ & $37.99 \%$ \\
\hline Inspiratory Reserve Volume (IRV) & (liter) & 2.75 & 0.10 & 3.78 & 0.20 & -1.04 & 0.20 & $25.57 *$ & $37.78 \%$ \\
\hline $\begin{array}{l}\text { Expiratory Volume In } 1 \text { First } \\
\text { Second Forced (FEV1) }\end{array}$ & (liter sec.) & 3.64 & 0.35 & 5.53 & 0.80 & -1.90 & 0.93 & $10.00 *$ & $52.16 \%$ \\
\hline Expiratory Reserve Volume (ERV) & (liter) & 1.24 & 0.09 & 1.61 & 0.17 & -0.37 & 0.19 & $9.76^{*}$ & $29.99 \%$ \\
\hline Peak Expiratory Flow Rare (PEFR) & (liter sec.) & 6.88 & 1.07 & 10.12 & 1.07 & -3.24 & 1.14 & $13.94 *$ & $47.12 \%$ \\
\hline
\end{tabular}

(t) value at the level of $0.05=2.069$ 
Table (6) and Figure (2) show that there are statistically significant differences at (0.05) in all physiological variables in favor to the post-measurement, where the calculated ( $\mathrm{t}$ ) value ranged between (9.76) and (25.57), which is greater than the tabulated $(\mathrm{t})$ value at $(0.05)=$ (2.069) with a percentage of improvement ranged between $(29.99 \%)$ and $(52.16 \%)$.

Figure (2)

Arithmetic mean of the pre- and post-measurements of the physiological variables

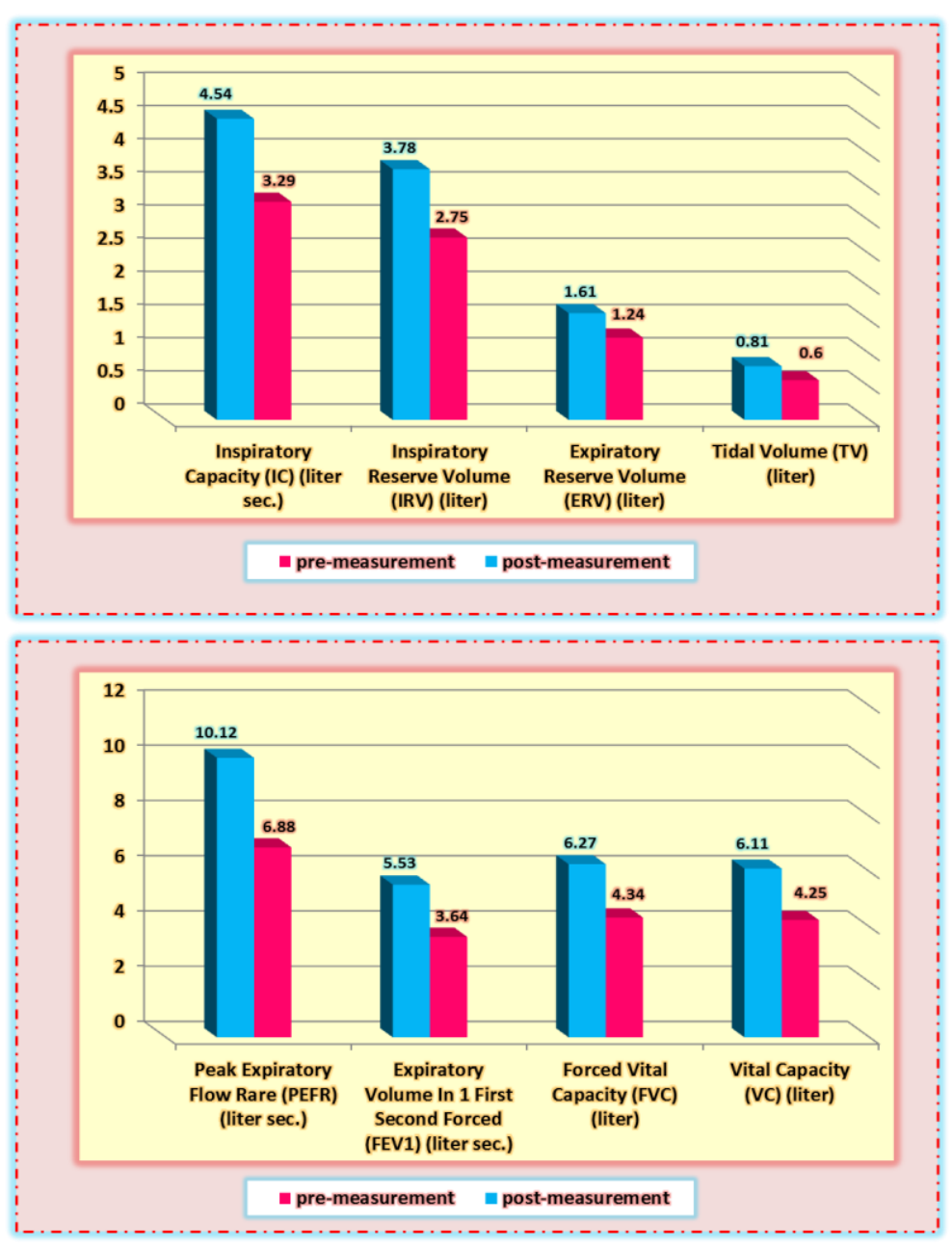


Table (7)

Statistical significances of the judges' evaluation scores for the performance level

of the sport show before and after the experiment $(n=5)$

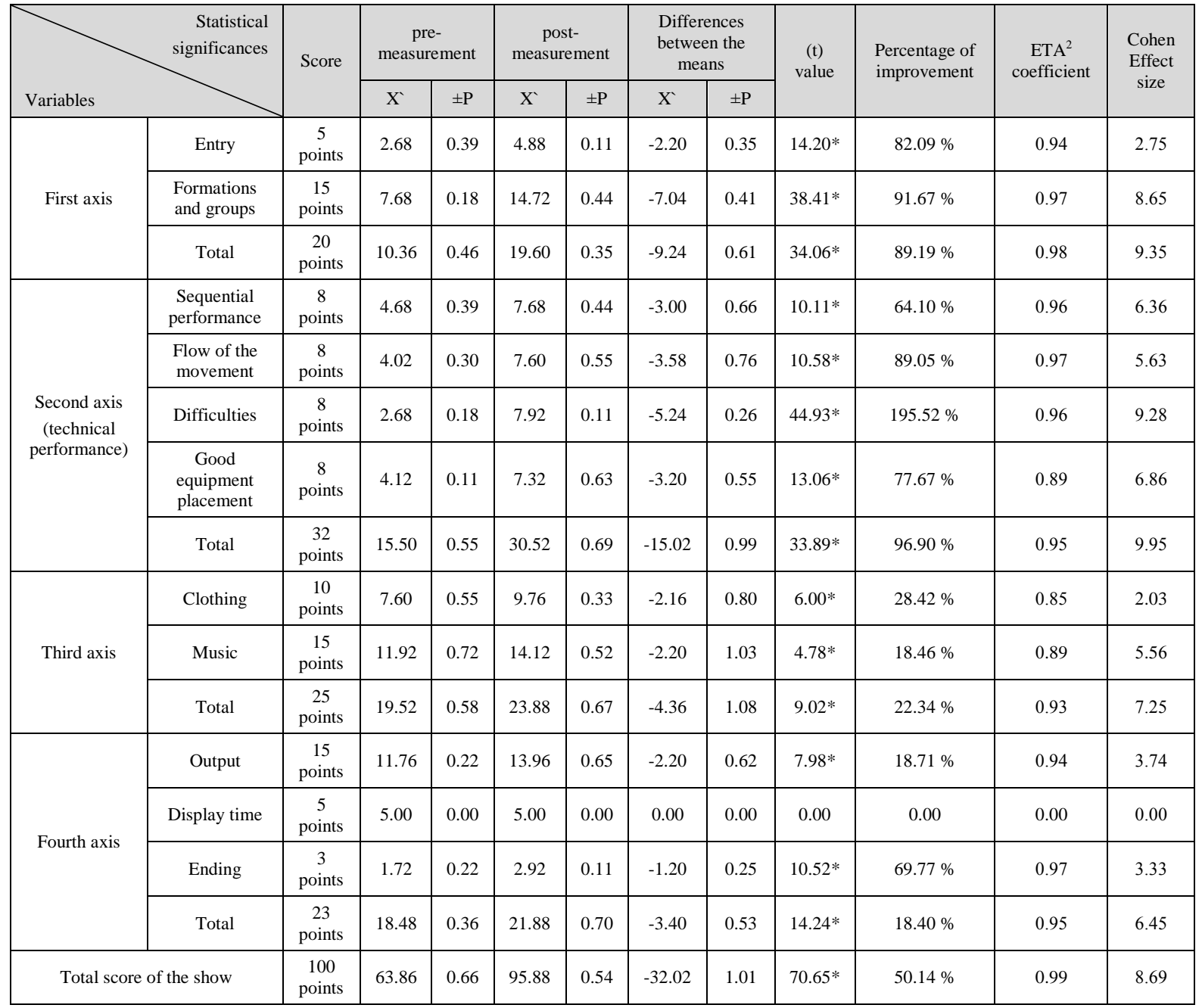

* tabulated $(t)$ value at the level of $0.05=2.78$

Table (7) and Figure (3) show that there are statistically significant differences at (0.05) in all elements except the "time" axis in favor to the post-measurement, where the calculated ( $\mathrm{t}$ ) value ranged between (4.78) and (44.93), which is greater than the tabulated $(\mathrm{t})$ value at $(0.05)=$
(2.78) with a percentage of improvement ranged between $(18.71 \%)$ and $(195.52 \%)$, also the values of the effect size of the sport show were high, ranging between (2.03 : 9.95), which is greater than 0.8. except the "time" axis with an effect size of (0.00). 
Figure (3)

Arithmetic mean of the pre- and post-measurements of the judges' evaluation scores for the performance level of the sport show
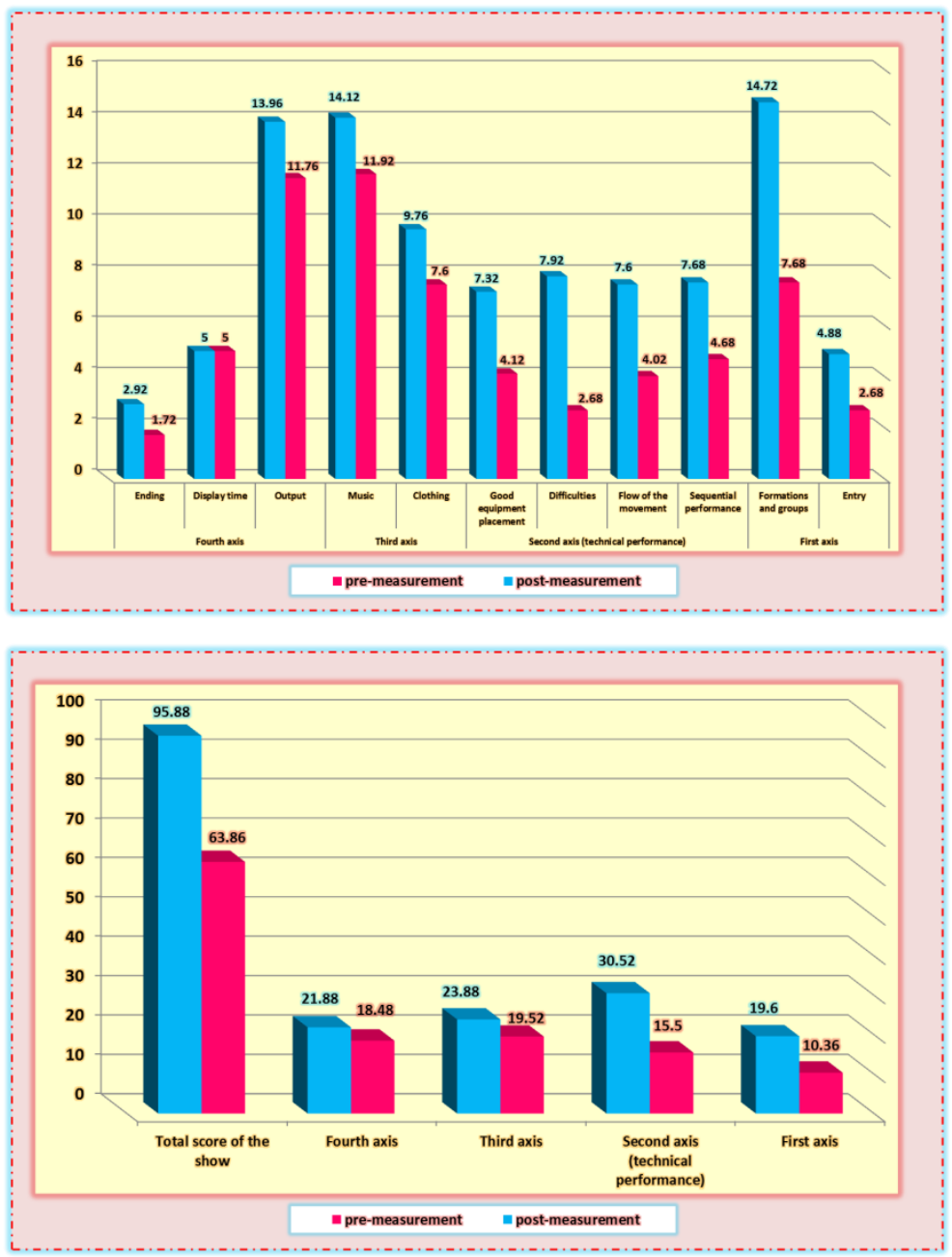

\section{Discussion of the results:}

Tables (5), (6) and (7) show that there are statistically significant differences between all of the physical and physiological variables in favor to the post-measurement at the significance level of 0.05 , as the high percentages of improvement indicate the development of students' level of the physical and physiological variables. The researchers attributed the high percentage of improvement of the physical variables and physiological indices to the positive effectiveness of the respiratory system as one of the aspects of adaptation to the sport show exercises, which were mainly aimed at affecting the physical and physiological variables as the respiratory system adapted to the regularization in preforming the training loads of the sport show.
By comparing the improvement of the physical variables, it was confirmed that the variables have improved due to the nature of the sport show exercises and the training method by switching the work with various intensities, which effectively improves the various physical abilities, as confirmed by the results of the study. (14) (17)(19) (39)

The level of efficiency of the physical effort in all types of physical activity changes through some phases which become obvious during the exercises and continue until fatigue and then begin to improve the level of physical efficiency during the recovery. $(1: 217)$

Sport training improves the respiratory muscles and the respiratory passages (10:53), and endurance exercises especially increase the strength of the respiratory muscles and thus improve the respiratory functions. $(10: 291)$ 
This is obvious in the lung function tests, which include assessing the gas exchange, the mechanical functions of the lung tissue and air paths, also assessing the mechanical functions of the lungs are done by comparing the sizes of the lung, the rates of air flow and the power of the respiratory muscles. $(5: 27)$

Sport activities, especially the endurance exercises increase the vital capacity as the player needs a quantity of air to get the largest amount of oxygen to increase its size in the blood, which leads to strengthening the muscles of the chest and increase the breathing rate and depth within the pulmonary circulation. (8:202), (20), (11:78), (35)

Regular training also leads to decreasing the work of respiratory functions, where the body needs less oxygen in athletes when performing the same effort compared to non-athletes. $(6: 26)$

Respiratory functions improve under the effect of sport training as the air now increases in one cycle (TV) and the air flow resistance is reduced, facilitating gas exchange. $(36: 114)$

Physiological adaptations that result from training improve the efficiency of oxygen delivery systems, which improve endurance, the decrease of energy when performing the muscular activity, the ability of maintaining the physical performance for the longest possible time. They also improve the aerobic ability and the work of the circulatory and respiratory systems due to the regular training. (9:85, 99)

Everson (2001) (20) and Parker (2006) (35) confirmed that the exercise increases the vital capacity (VC). The player needs a quantity of air to have the largest amount of oxygen to increase the size of blood which then strengthen the muscles of the chest and increase the rate of breathing and depth in circulation.

Abdel-Maksoud (1994) and Abdel Monaem Bedair (2010) note that the codified training programs develop the physiological abilities for the circulatory and respiratory systems, as well as adapting the functions of the lungs, where the chest cavity increases, the respiratory muscles power improves, the size and depth of the breathed air increases, the capillaries gets enlarged, which finally lead to increasing the size of gas exchange. These reactions are doubled if the training begins early, and regarding the top level athletes who practice endurance activities can achieve high levels.

$(15: 148),(1: 89)$
The results of El-Sayed Moustafa (2002), Hayes (1998) and Lakhera et al. (1994) confirmed that endurance training improves the function of the lungs by increasing the muscular strength within the ribs and the diaphragm muscles, improving the size of the breathed air, increasing the ability of the muscles to push the air out of the lungs and then increase the forced vital capacity.

$(16: 96),(22: 6,50),(28: 258)$

The researchers attributed the increase of forced vital capacity (FVC) to the positive effect of the sport show exercises, which improved the physiological performance of the two lungs as a result of increasing the power of the breathing muscles and increasing the depth of air size which leads to increasing the size of the forced vital capacity.

Improving the size of forced expiratory volume in 1 second (FEV1) can be achieved due to the effectiveness of sport show exercises, including the various exercises that develop the different fitness elements.

Ahmed Ibrahim \& Magda Hammouda (2000), Doherty \& Dimitriou (1997) show that aerobic exercises reduce the resistance of the air paths, which helps to increase breathing depth and release the largest amount of air through exhalation at the end of the first second. (4:406), $(12: 337)$

In addition to improving the endurance level of the breathing muscles (38:96), increasing the size of the breathed air inhaled in a single cycle (TV), and decreasing air flow resistance, which facilitates the exchange of gases. $(36: 114)$

The results of the study show the positive effect of the sport show exercises on improving peak expiratory flow rare (PEFR). The researchers attributed the improvement to the sport exercise exercises which included exercises that develop the strength of the abdominal and chest muscles that support the breathing muscles in increasing the rate of air flow to the inside and outside the lungs. The improvement in the rates of air flow is related to the physiological development. Peroux et al. (1995) point that the velocity of inhaling and exhaling is linked to the strength and efficiency of the breathing muscles. (37)

The results of this study are consistent with the results of the studies of Sohair Mahfouz (1992), Lucia et al. (2001), which showed a significant correlation between the effect of sport training and the rate of air flow velocity. (43:181) $(29: 133)$ 
Hogeveen (2000) also point that the high intensity training has an effect on improving the respiratory system efficiency faster than that of the low intensity training (24 :45)

Azmy Faisal (2002) confirms that the anaerobic physical loads have a greater impact on the respiratory responses and the level of respiratory functions than the aerobic loads. (7)

The physiological changes that occur as a result of physical effort are obvious in the improvement of the respiratory functions which improve by practicing the exercises, and thus changes before, during, and after the exercise. (46:132) $(44: 45)$

Sport training has positive effects in improving the respiratory functions and pulmonary ventilation, reducing the number of breathing times required to move the same amount of air before training, and increasing the level of capillaries in order to increase the process of gas exchange. (22:60) (42:89, 90) (45:226). That was confirmed by the results of the studies. (3) (30)

\section{Conclusions:}

1- The research group in the post-measurement exceeded the pre-measurement in all of the physical variables under study.

2- The research group in the post-measurement exceeded the pre-measurement in all of the physiological variables of the respiratory and circulatory systems.

3- The improvement of the performance level in the sport show in the post-measurement was better than the premeasurement.

\section{Recommendations:}

1- Directing the students to participate in the sports shows that contribute to the improvement of the physical variables.

2- Directing the students to participate in the sports shows that contribute to the improvement of the physiological variables of the respiratory and circulatory systems.

3- Using and functionalizing the exercise tools and equipment in the sport shows appropriately.

4- Conducting the physiological measurements regularly to identify the extent of the response of the respiratory and circulatory systems to meet the requirements of the sport shows of the students of the Faculty of Physical Education.

\section{References:}

1- Abdel-Monaem Bedair El-Qassir (2010): Physiology of Sport, Alexandria.

2- Abu-Elela Abdel-Fattah, Mohamed Sobhy Hassanein (1997):Sport Physiology and Morphology and Methods of Measurement and Evaluation, Dar Al-Fikr Al-Araby, Cairo.

3- Adel Ramadan (2001):The Effect of Developing Anaerobic Ability at the End of the Training Session on Some Physical and Physiological Variables and the Basic Techniques of Basketball for (16-18 years) Juniors, PhD thesis, Faculty of Physical Education in Port Said, Suez Canal University.

4- Ahmed Ibrahim, Magda Hammouda (2000):The Effect of Training Loads According to the Characteristics of the Biorhythm Pattern on the Values of Some Indices of the Respiratory System, Journal of Theories and Applications, Faculty of Physical Education for Boys, Alexandria University, No. 38.

5- Alassad , K., karlinskyo,J.B.,(1997):Pulmonary function testing, $\mathrm{N}$ :A practical approach to pulmonary medicine edited by, Goldstein, R.H, Connell, J.J., Karlinsky, J. B., Lippincott -Reven, Philadelphia,U.S.A.

6- Alge V Alfonsas V Virginija S Jonas p(2004):The influence of aerobic exercise to cardiovascular physiological parameters of 30- 40 year old women Kaunas University of medicine Lithuanian academy of physical education.

7- Azmy Faisal El-Sayed (2002): Effectiveness of Step Exercises to Improve the Level of Aerobic and Anaerobic Energy Systems for the 13-15 Years Age Group. Master's thesis, Faculty of Physical Education, Alexandria University.

8- Bahaa El-Din Salama (2008): Biochemical Characteristics of Sport Physiology, 1st Edition, Dar AlFikr Al-Araby

9- Bahaa El-Din Salama (2009): Physiology of Physical Effort, Dar Al-Fikr Al-Araby, Cairo.

10- Celli, B.R, (1997): Pulmonary rehabilitation ,N:A practical approach to pulmonary medicine ,edited by Goldstein, R.H, Connell, J.J., Karlinsky, J. B., Lippincott -Reven, Philadelphia,U.S.A,. 
11- Dick, F.W., (1997): Sports Training Principles, 3rd ed., A\&C Black. London

12- Doherty, M., Dimitriou, 1.,(1997): Comparison of Lung Volume In Greek Swimmers, land Based Athletes, and Sedentary Controls Using Allometric Scaling, Bri. J . sports Med., Dec.

13- Ehab Mohamed Emad El-Din (2016): Modern Laboratory Measurements (Physical - Physiological Textural - Physical Composition), World of Sport for Publishing, Alexandria.

14- El-Said Abu-Bakr (2012): The Effect of Aerobic and Anaerobic Exercises on the Physical and Physiological State of the Students of the Faculty of Physical Education in Alexandria, Master's thesis, Faculty of Physical Education for Boys, Alexandria University.

15- El-Sayed Abdel-Maksoud (1994): Endurance Training and Physiology, Al-Shabab Free Press, Alexandria.

16- El-Sayed Moustafa Hassan (2002): The Effect of Training on Developing the Effectiveness of Performance in Some Physiological Responses during the Preparation of 14-16 Years Junior Boxers, Master's thesis, Faculty of Physical Education for Boys, Alexandria University.

17- Emad Abdel-Samie (2005): The Effect of Energy Fitness Training Using Aerobic and Anaerobic High Intensity Periodic Sprint and Regressive Sprint on the Development of Velocity, PhD thesis, Faculty of Physical Education for Boys, Helwan University.

18- Essam Abdel-Khalek Moustafa (2005): Sport Training, Theories and Applications, 8th Edition, Dar AlMa'aref, Alexandria.

19- Essam Amin Helmy (1998): Training Strategy of Swimming for Juniors, Dar Al-Ma'aref Alexandria.

20- Everson .M., (2001): The Measurement of Physiology ZAN - 680 ergo spirometry system ZAN messgract, Gmbh . by 7723 ober thulba Germany .

21- Gallahue, L.D., (1993): Development physical Education Of Today Elementary Children, 1 St., ed., Macmillan publishing .

22- Hayes ,F., (1998): The Complete Guide To Cross Training A\&C Black London

23- Hessein Heshmat, Mohamed Salah El-Din (2009): Biology of Sport and Health, Book Center for Publishing, Cairo.
24- Hoogeveen, A. R., (2000): The Effect Of Endurance Training On the Ventikatory Response To Exercise In Elite Cyclists Eur. J. Appl. Physiol., May Vol. 82 (1-2), PP. 45- 51.

25- Howly, E.T, Franks, B.D,.(1997): Health fitness instuctors handbook, 3rd, ed. Human Kinetics champaign, , U.S.A..

26- Kudo, E., (2008.): The Martial Arts Education in Akita Han, http://ci.nii.ac. Jp/naid/110001919939/en,

27- Laila Abdel-Aziz Zahran (1997): Scientific and Practical Basics of Exercises, Dar Al-Fikr Al-Araby, Cairo.

28- Lakhera SC1, Kain TC, Bandopadhyay P. (1994): Changes in Lung Function During Adolescence in Athletes and Non - Athletes, J. sports Med. Physiology Fitness, Sep . Vol. 34. 1994.

29- Lucía Alejandro, Jesús Hoyos, Javier Pardo, José L. Chicharro., (2001): Effects Of Endurance Training On The Breathing Pattern Of Professional Cyclists, Jpn. J. Physiol. Apr. Vol. 51 (2), PP. 133- 141.

30- Mahmoud Mohammed (2007): The Effect of Aerobic and Anaerobic Exercises on Plan Preparation and the Level of Achievement for the Fencing Players, $\mathrm{PhD}$ thesis, Faculty of Physical Education, Tanta University.

31- Mofty Ibrahim Hammad (2009): Sport Training for Juniors and the Successful Trainer, Modern Book House, Cairo.

32- Mohamed Hassan Allawy, Mohamed Nasr El-Din Radwan (2001): Kinetic Performance Tests, Dar Al-Fikr Al-Araby, Cairo.

33- Mohamed Sobhy Hassanein (2005): Measurement and Evaluation in Physical Education and Sport, Part I, 6th Edition, Dar Al-Fikr Al-Araby, Cairo.

34- Mohammed Nasr El-Din Radwan, Khalid bin Hamdan Al Masoud (2013): Physiological Measurements in Sport Field, Book Center for Publishing, Cairo.

35- Parker, R; (2006)::The velocity star training system is a3 phase complete. velocity and quicknees training program greater performance in simply the best in velocity training equipment. GPI - US Track.

36- Prentice .W.E.,(1997): Fitness for college and life, 5th ed, Mosby-year book, ink, U.S.A. 
37- Prioux J , Mercier J , Ramonatxo M , Granier P , Mercier B , Prefaut C ., (1995): Evolution of Breathing Pattern And Ventilation At Maximal Exercise During Growth, Seances, Soc. Biol. Fil., Vol. 189 (2), PP. 313332.

38- Said Salem (2012): The Effect of Using the Rope and Treadmill Exercises on Some Physical and Physiological Variables for the 9-12 Years Age Group, Master's thesis, Faculty of Physical Education for Boys, Alexandria University.

39- Salim,E,M.\&Hammad, E,S.(2015): Physical and Physiological Responses Associated to Rope and Stepping Box Exercises in Students of the Faculty of Physical Education, journal of applied sports science ,vol.5,No.1, the Faculty of Physical Education for men, Alexandria University, march .

40- Samir Abdel-Naby Issa (2007): The Effect of Sport Shows on the Dynamics of Development of Some Sensory-Motor Variables and the Level of Practical Achievement in Exercises for the Students of the Faculty of Physical Education, PhD thesis, Faculty of Physical Education, University of Alexandria.
41- Sharkey, BJ,( 1997): Fitness For Sport, N:Successful Coaching - A Publication For The American Sport Education Prohram And The National Federation Interscholastic Coaches Association, Edited By, Martens R., 2ndEd., Human Kinetics,U.S.A.

42- Sharkey,B.J.,(1997): Fitness and health, 4th ed., human kinetics, U.S.A,.

43- Soheir Mahfouz (1992): The Effect of Aerobic Exercise on Some Blood Components, Respiratory Functions and the Digital Level of the $1500 \mathrm{~m}$ race, Scientific Journal of Physical Education, No. 3, July, Faculty of Physical Education for Girls, Alexandria University.

44- Wall, j., \& Murray,N .,(1995): Children\& Movement, physical education in the Elementary school, 2 nd, Brown \& Benchmark, U.S.A .

45- Wilmore, J,H., \& Costill, D.L .,(1994): Physiology of sport and exercise, human kinetics, U.S.A.

46- Youssef Kammash, Saleh Bashir (2011): Introduction to Sport Biology: Dar Al-Wafa for Publishing, 1st Edition, Alexandria. 